\title{
Correlation of Toxic Product Yields from Tube Furnace Tests and Large Scale Fires
}

\author{
T. RICHARD HULL, KRZYSZTOF LEBEK, and KEITH T. PAUL \\ Fire Materials Group, CMRI \\ Bolton Institute \\ Deane Road \\ Bolton, BL3 5AB, UK
}

\begin{abstract}
Toxic product yields obtained from a steady state tube furnace method (the Purser furnace, IEC 60695-7-50) are compared with results reported for a static tube furnace (suitable for IEC 60754-2) and a large scale test (the European Horizontal Reference Scenario Test for cables, enclosed in an ISO 9705 room). Data for burning polypropylene as a function of equivalence ratio shows excellent correlation between small and large scale. Results from four commercial cable types are also reported, and compared with static tube furnace data, and the horizontal reference scenario now accepted for European cable flammability assessment. These show varying degrees of correlation, as may be expected given the complex nature of cable construction and burning and the large differences between the fire types involved.
\end{abstract}

KEYWORDS: fire chemistry, toxicity, cables, PVC, polypropylene, carbon monoxide

\section{INTRODUCTION}

The majority of deaths in fires result from inhalation of toxic gases [1]. The yield of toxic gases from these materials is dependent on both the fire conditions and the material formulation [2]. In general, large scale ventilation-controlled fires generate far higher concentrations of toxic products than small-scale well-ventilated fires. The present work compares the bench-scale yields of toxic products from polypropylene with those from a large scale fire as a function of equivalence ratio, $\phi$. It goes on to compare bench scale toxic product yields of whole cables with results from another reported bench scale test, and a large scale test.

Electric cables frequently present a high fire risk of ignition, because of the heating effect of electric currents, and the remote locations of their installation, and the increased quantities of communication and power cables in place. This high risk translates into a significant hazard because cables are frequently installed in ventilation ducting and other channels which may breach the normal fire enclosures within a building. This means that a cable fire can spread unnoticed from compartment to compartment.

Until recently, fire (or smoke) toxicity was only specified for certain high risk applications. Estimation of lethal toxic potency of fire effluents is of increased importance as prescriptive standards of fire behaviour for product acceptance are replaced by holistic performance based fire codes allowing a wider range of materials to be selected. Architects can now specify that new buildings now require assessment by fire safety engineers in terms of flammability and fire gas toxicity within the time required to escape [3]. 


\section{Fire Types}

The yields of toxic products are highly dependant on the fire conditions. As an enclosure fire develops, the temperature increases and oxygen concentration decreases. This has been set out as series of characteristic fire types [4], from smouldering to post-flashover.

\section{Real-Scale Fires}

Large scale fire tests, where transition through the different fire types occurs, show the highest levels of the most toxic species $\mathrm{CO}$ (and coincidentally also HCN) under oxygendepleted conditions. These are the conditions where the heat flux is sufficient to drive the decomposition and pyrolysis processes forward, but there is insufficient oxygen to allow the combustion reactions to go to completion. The factors controlling a material's fire gas toxicity are generally poorly understood, but have been shown to be somewhat independent of material for many non-fire retarded $\mathrm{C}, \mathrm{H}$, and $\mathrm{O}$ polymers [5], and highly dependent on fire conditions. The difficulties in predicting large scale behaviour on a small-scale have left this area neglected in the development of fire retarded materials.

\section{Physical Fire Models and Steady State Burning}

Fully-developed fire conditions are difficult to replicate in bench-scale tests, and most bench-scale fire models are more suited to replicating the much less toxic early, wellventilated fire types. Some other physical fire models enclose the burning sample, which starts off well-ventilated, but becomes increasingly oxygen depleted during burning. Neither the well-ventilated, nor the closed box methods provide the data the fire safety engineers require to predict the toxicity of developed fires. The defining feature of fully developed flaming is that the rate of burning is controlled by the air feed rate, not by the fuel supply or radiant flux. To replicate this on a small-scale requires control of the air feed rate for a particular burning rate. Small scale physical fire models for the prediction of toxic product yields can only relate to fully developed low-ventilation fire types when the air feed rate is fixed for a particular rate of burning.

\section{Standard Methods}

One of the only bench-scale physical fire models capable of replicating a ventilation controlled steady state is the tube furnace apparatus [6] (known as the Purser furnace, Fig. 1). The apparatus differs from those described above (the well-ventilated and closed box apparatuses) in that the sample is fed into the tube furnace at a fixed rate (typically $1 \mathrm{~g} \mathrm{~min}^{-1}$ ) alongside a fixed air flow, which may be above, at, or below the stoichiometric (chemical) air requirement. As the sample moves into the furnace, so it experiences increasing radiant flux intensity, until it ignites, then the flame spreads backwards to a slightly cooler part of the furnace. At low oxygen concentrations, or for fire retarded materials, where ignition is more difficult, the sample reaches a hotter part of the furnace before igniting, and again, the flame will stabilise itself, as it spreads a little way back up the tube. For samples of known composition, especially those which burn completely, such as polypropylene, it is a simple matter to preset the equivalence ratio and hence the fire condition. For samples of unknown composition, especially highly fire retarded materials, it is more difficult to preset the fire condition. The standards BS 7990:2003 and IEC 60695-7-50:2002 describe two methods capable of making such measurements in this apparatus. The two standards differ in the methodology used to define the fire types. In real-scale under-ventilated fires, the fire will grow until it is limited by the oxygen 
supply. In bench-scale tests, the oxygen requirement must be known in order to simulate this. Since typical polymer-based materials may contain up to $70 \%$ inorganic fillers, it is not always possible to know the fuel content, and hence the oxygen requirement of the material. IEC 60695-7-50 defines extremes of under and over-ventilation, which ensure that the conditions have been met. BS 7990 uses the more sophisticated equivalence ratio approach, where the oxygen requirement is determined beforehand, and then the underventilated conditions are replicated by using twice the stoichiometric fuel/air ratio. These differences are illustrated in Table 1.

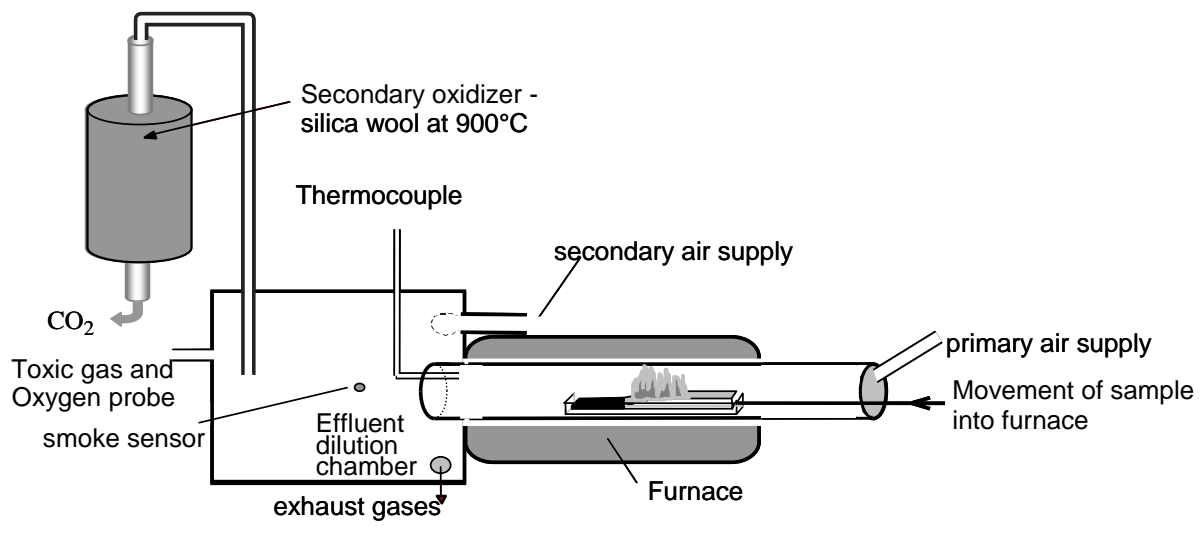

Fig. 1. The steady state tube furnace apparatus (Purser furnace).

Table 1. Furnace conditions corresponding to characteristic stages of burning behaviour.

\begin{tabular}{|l|c|c|l|}
\hline Fire Type & $\begin{array}{l}\text { Temp. } \\
\left({ }^{\circ} \mathrm{C}\right)\end{array}$ & $\begin{array}{l}\text { IEC 60695-7-50 } \\
\text { Primary air flow } \\
(\mathrm{l} / \mathrm{min})\end{array}$ & $\begin{array}{l}\text { BS 7990 } \\
\text { Primary air flow } \\
(\mathrm{l} / \mathrm{min})\end{array}$ \\
\hline $\begin{array}{l}\text { 1b Smouldering } \\
\text { (non flaming } \\
\text { fires) }\end{array}$ & 350 & 1.1 & 2 \\
\hline $\begin{array}{l}\text { 2 Well ventilated } \\
\text { flaming }\end{array}$ & 650 & 22.6 & 10 \\
\hline 3a Early Flaming & 650 & & $\begin{array}{l}\text { Twice stoichiometric fuel/air ratio } \\
\text { based on result of 2 above. }\end{array}$ \\
\hline $\begin{array}{l}\text { 3b Fully } \\
\text { developed (under } \\
\text { ventilated) fires }\end{array}$ & 825 & 2.7 & $\begin{array}{l}\text { Twice stoichiometric fuel/air ratio } \\
\text { based on result of 2 above. }\end{array}$ \\
\hline
\end{tabular}

In this work, results for a material of known composition obtained at different equivalence ratios are compared to full-scale, and data obtained from burning cables under well-ventilated conditions are compared to product yields for a well-ventilated fire using 22.6 litres of air per gram of material, at $650^{\circ} \mathrm{C}$ are reported. 


\section{Materials vs. Products}

The tube furnace methods are generally applicable to materials, which are used in pellet or granulated form. However, the design of cable materials have an inhomogeneity, which is unlikely to be accurately represented by adding the fire toxic product yields of burning the individual components. A typical cable will have a fire retarded sheath surrounding a more flammable core of insulation material, such as LDPE, separating the individual copper conductors. Fortunately, their linear construction makes cables up to 1 $\mathrm{cm}$ diameter ideal for tube furnace work, where they can be burned whole.

\section{CARBON MONOXIDE YIELD AS A FUNCTION OF EQUIVALENCE RATIO}

A study of low density polyethylene (LDPE), vinyl acetate-ethylene copolymers (19\% EVA and 26\% EVA), polypropylene (PP) and polystyrene (PS), and polymethylmethacrylate (PMMA) shows the variation of CO yield as a function of equivalence ratio [5]. The different equivalence-ratio conditions were created by varying the mass of sample, so as to keep the oxygen requirement constant for the range of polymers. The equivalence ratio for a particular polymer may then be varied by varying the primary (furnace tube) air flow rate. In this way carbon monoxide concentrations, can be directly compared for a range of fire conditions and a range of polymers. The furnace was set at a nominal temperature of $750^{\circ} \mathrm{C}$, corresponding to a maximum furnace air temperature ranging from $710-740^{\circ} \mathrm{C}$ depending on air flow rate. By adjusting the mass of polymer to the corresponding oxygen requirement, the primary air flow could be kept constant at each $\phi$ ratio, in order to ensure identical conditions in the furnace. The equivalence ratios used were $\phi=0.5$ and 0.7 (fuel lean), $\phi=1.0$ (stoichiometric) and $\phi=$ 1.5 (fuel rich).

These results (Fig. 2) show that the general rule that all small scale fire tests underpredict CO yields [7] does not apply to the Purser furnace. The CO yields in full scale flashover fires are approximately $0.2 \mathrm{~g} / \mathrm{g}$, which corresponds to the levels found in this work. For well-ventilated conditions this shows the CO yield is low, but significant.

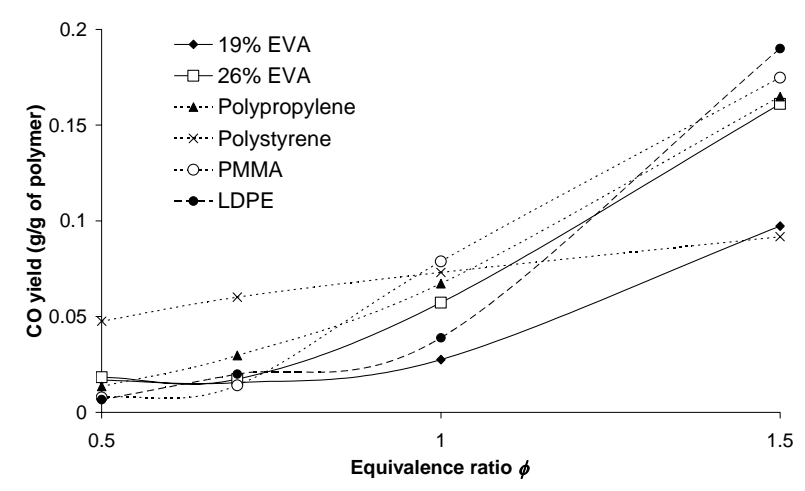

Fig. 2. Variation of CO yield with equivalence ratio $\phi$.

There is a clear correlation of CO yield with equivalence ratio. For non-aromatic hydrocarbon, and partially oxygenated fuels, this is independent of the fuel, and depends only on the equivalence ratio. As predicted in the calculation, and reported in other work, the $\mathrm{CO}$ yield starts to rise around an equivalence ratio of $\phi=0.7$. For stoichiometric and fuel rich conditions, the $\mathrm{CO}$ yield increased significantly, rising to between 0.16 and 
$0.19 \mathrm{~g} / \mathrm{g}$ at $\phi=1.5$ for all the fuels except polystyrene and the 19\% EVA. Polystyrene has the highest value at low equivalence ratios, but the lowest value at high equivalence ratios, and does not fit into the general pattern. The higher $\mathrm{CO}$ yield and correspondingly higher soot yield for aromatics and unsaturated fuels burning in well ventilated conditions is well known. In a larger scale enclosure fire, Beyler [8] reported a CO yield of $0.11 \mathrm{~g} / \mathrm{g}$ for toluene under fuel rich conditions, and attributed this to the thermal stability of the molecule, and hence the reduction in the availability of $\mathrm{OH}$ - for the reaction in Eq. 1 which is largely responsible for $\mathrm{CO}_{2}$ formation.

$\mathrm{CO}+\mathrm{OH} \cdot \rightarrow \mathrm{CO}_{2}+\mathrm{H} \cdot$

Since the main product of decomposition of polystyrene is the monomer, with smaller quantities of dimmer, trimmer and tetramer, these are also likely to show similar enhancements in thermal stability, limiting the availability of $\mathrm{OH} \cdot$ radicals.

This work corresponds with that reported [9] on the global equivalence ratio at temperatures greater than $625^{\circ} \mathrm{C}$, with an upper layer exclusively from the fire plume. That work suggests that the CO yield will remain at a constant value of $0.2 \mathrm{~g} / \mathrm{g}$ of polymer for equivalence ratios greater than 1.5 , but these were not covered in this study.

Work reported in the main test series in the TOXFIRE project [10], where a phi meter [11] was used to establish the fire condition, shows the same trend in $\mathrm{CO}$ yield for the steady state tube furnace and the tests performed inside a lightweight concrete room with dimensions in accordance with the ISO 9705 (Fig. 3). The difficulty in establishing ventilation conditions in the pool fire (where the CO yield was $0.09 \mathrm{~g} / \mathrm{g}$ at $\phi=0.5$ ) and storage configuration (CO yield $0.295 \mathrm{~g} / \mathrm{g}$ at $\phi=1$ ) in the large scale test enclosure may have contributed to the deviation from this trend. In well-ventilated conditions, both the tube furnace and the large scale fire give CO yields around $0.02-0.03 \mathrm{~g} / \mathrm{g}$, rising to $0.17 \mathrm{~g} / \mathrm{g}$ in the tube furnace and $0.1 \mathrm{~g} / \mathrm{g}$ in the large scale test for under-ventilated flaming.

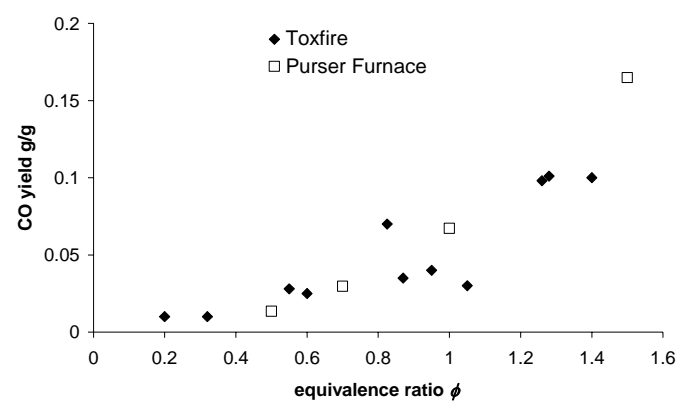

Fig. 3. Comparison of $\mathrm{CO}$ yields versus $\phi$ for Purser furnace and real scale.

\section{TOXIC PRODUCT YIELDS FROM BURNING CABLES}

All the cables studied were of comparable flammability, having passed the single wire burning test IEC 60332-1, thus satisfying the industry standard criteria for general applications. Four different cable compositions were investigated, one data cable based on PVC (Cat. 5) and three power cables one based on PVC (NYM) and the other two on 
polyolefin polymers (NHMH formulated with Casico ${ }^{\mathrm{TM}}$ ) and a cross-linked formulation (NHXMH). All four cables were supplied by Borealis AB (Sweden). Formulations followed standard industry practice. Only the outer sheath was made of a different material, with the inner using polyolefin insulation, except for the PVC power cable which had PVC for sheath, bedding and insulation. The PVC materials contained PVC, plasticizer (di-iso-octyl phthalate from GC-MS analysis) and chalk. Thermogravimetric analysis showed small differences in composition between the samples of PVC cables which were from different sources for the different tests. One polyolefin material, Casico, contains ethylene-acrylate copolymer, chalk (30\%) and silicone elastomer. This forms an intumescent structure during heating; the flame retardant mechanism of Casico is complex and is related to a number of reactions [12].

\section{Comparison with Small Scale Test Data}

The data are compared with those obtained by decomposing $0.3-1.0 \mathrm{~g}$ of sheathing material in a static tube furnace for 15 minutes at a furnace temperature of $575^{\circ} \mathrm{C}$ and an air flow of 2 litres $\min ^{-1}$. This used an apparatus similar to that used for the IEC 60754-2 test. The product yields were calculated from the gas analysis reported elsewhere [13-15]. In this section the yields are compared on an initial mass of polymer compound basis. The two methods differ in that the steady state (Purser) furnace used whole cables, and involves moving the sample into a hotter part of the furnace with a relatively large volume air flow of 22.6 litres $\mathrm{min}^{-1}$, while the static furnace method used cable sheathing material, and placed the sample in the hottest part of the furnace, with a smaller air flow. While the lower air flow and fixed position in the furnace may lead to more stable flaming over the sample, the lower temperature and small sample mass would mitigate against this.

Figure 4 shows the $\mathrm{CO}_{2}$ yield in grams $\mathrm{CO}_{2}$ per gram of initial compound mass. Although most of the $\mathrm{CO}_{2}$ arises from combustion processes, these samples all contain significant amounts of chalk, which could release $\mathrm{CO}_{2}$ by release of $\mathrm{HCl}$ from the decomposing PVC (Eq. 2).

$\mathrm{CaCO}_{3}(\mathrm{~s})+2 \mathrm{HCl}(\mathrm{g})$ (from polymer) $\rightarrow \mathrm{CaCl}_{2}(\mathrm{~s})+\mathrm{CO}_{2}(\mathrm{~g})$

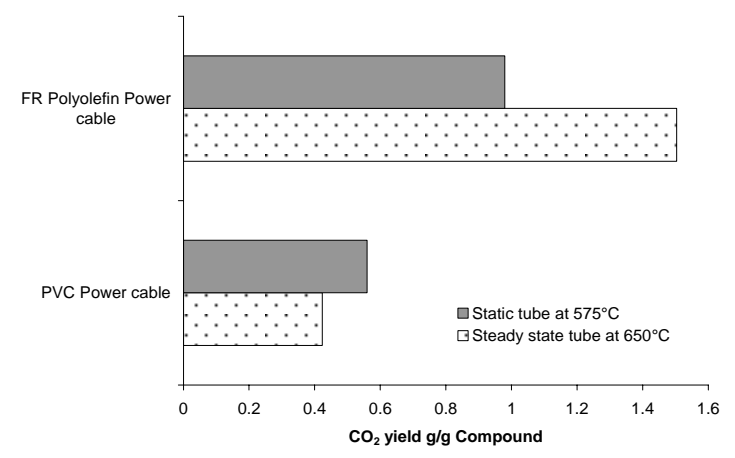

Fig. 4. Comparison of $\mathrm{CO}_{2}$ yield per gram of initial polymer compound.

Alternatively, if flaming allowed the sample temperatures to reach $800^{\circ} \mathrm{C}, \mathrm{CaCO}_{3}$ would decompose to $\mathrm{CaO}$ (Eq. 3). 
There is reasonable agreement between the $\mathrm{CO}_{2}$ yields for the fire retarded polyolefin and the PVC power cable, showing the completeness of combustion in the different decomposition conditions. The similarity of the CO yields (Fig. 5) points to a higher proportion of carbon in the residue for the polyolefin cable, and more products of incomplete combustion (particularly CO) in the steady state tube furnace for PVC.

The CO yields in Fig. 5 from the two methods show greater differences, illustrating the sensitivity of $\mathrm{CO}$ formation to the conditions. Carbon monoxide results from incomplete combustion. This can arise from:

- Insufficient heat (e.g., during smouldering).

- Quenching of the flame reactions (e.g., when halogens are present in the flame, or ventilation overcools the flame).

- Insufficient oxygen (e.g., in post-flashover fires, large radiant heat fluxes pyrolyse the fuel even though there is not enough oxygen to complete the reaction).

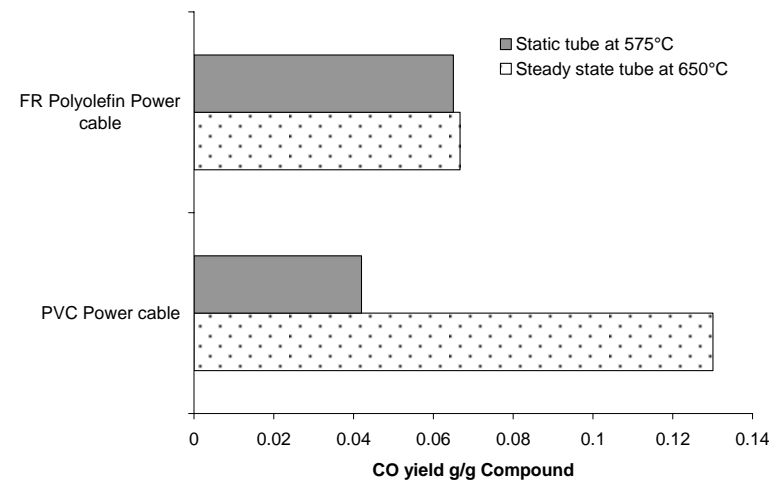

Fig. 5. Comparison of CO yield per gram of initial polymer compound.

Surprisingly, the CO yield was significantly lower for the PVC cable in the static tube furnace at $575^{\circ} \mathrm{C}$ than in the steady state tube furnace at $650^{\circ} \mathrm{C}$, suggesting more complete combustion in the slower air flow. The inhibiting effect of the $\mathrm{HCl}$ on conversion of $\mathrm{CO}$ to $\mathrm{CO}_{2}$ for the PVC power cable seems to be more evident in the higher air flows of the steady state tube furnace.

The yield of $\mathrm{HCl}$ from PVC cable material in the static tube furnace was reported as $0.15 \mathrm{~g} / \mathrm{g}$. The yield of $\mathrm{HCl}$ from the whole cable in the steady state tube furnace was $0.099 \mathrm{~g} / \mathrm{g}$ compound, and an additional $0.006 \mathrm{~g} / \mathrm{g}$ was detected as organochlorine compounds (as the difference between the $\mathrm{HCl}$ detected from the effluent dilution chamber and the secondary oxidiser). It is recognised that $\mathrm{HCl}$ is easily lost by attachment to surfaces, but the wet analysis method had previously been shown to account for over $90 \%$ of the $\mathrm{HCl}$ from decomposing rigid PVC. However, the inside surfaces of the apparatus were covered in fine needle like crystals (thought to be of plasticizer, or its decomposition product) which may have increased $\mathrm{HCl}$ losses. It is probable that different levels of $\mathrm{HCl}$ trapping occurred (the gentle temperature ramp of 
the tube furnace would favour trapping of released $\mathrm{HCl}$ by the chalk, compared to the rapid rise of a sample placed directly in a furnace at $575^{\circ} \mathrm{C}$. In a real fire, the heating rates are likely to vary between these two extremes.

\section{Comparison with Large Scale Test Data}

The data obtained, as described in the preceding section, are compared with limited large scale test data. These use the horizontal reference scenario (Fig. 6), which has been accepted as the standard test method for Euroclassification of electric cables by the European Commission's Expert Group on Fire (which has replaced the previous Fire Regulators Group). This horizontal test set-up, identified as most efficient for differentiating cable fire performance, consists of a closed horizontal configuration with no end wall (e.g., corridor configuration), no side walls in contact with cable ladders, and no forced ventilation. It uses a propane burner with heat source programme moving upwards from $40 \mathrm{~kW}$ to $100 \mathrm{~kW}$ after 5 minutes (and if necessary to $300 \mathrm{~kW}$ after a further 10 minutes), for 10 minutes and has three cable ladders installed one above the other. By removing the front wall, the Swedish testing laboratory SP were able to enclose the test assembly within the ISO 9705 Room Corner apparatus. Thus the test procedure could follow a standard published test method with only the specimen installation requiring separate specification. This paper has used the data reported from that work [14].

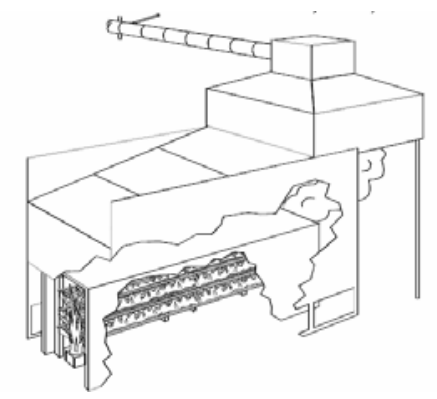

Fig. 6. The horizontal reference scenario for testing cable flammability.

In spite of the horizontal orientation this test is severe due to radiant reflection from the side walls and interaction between the three installed cable ladders. Results indicate it is only slightly less severe than the vertical reference scenario. Soon after ignition of the burner the cables on the lower ladder, just above the burner, ignite. Next the cables on the middle ladder ignite, and subsequently those above on the third ladder. At this point the fire is confined to the area immediately above the burner. Subsequent propagation occurs along the top ladder due to strong convective airflow induced by the burning cables and the contribution due to increasing burner energy. Dripping is especially damaging as this is the major route by which fire spreads from the upper ladder to those below. For products having limited fire retardancy all cables are alight within the first 5 minutes ( $40 \mathrm{~kW}$ burner). During the latter stages of the test, convective airflow is significant in drawing more air to the burning cables. However, it represents an essentially wellventilated scenario, of much greater complexity than the tube furnace. Further, since the cable mass loss was not recorded, it was estimated by oxygen depletion calorimetry, using the heat of combustion of the cable materials. This assumes a uniform loss of 
material, and would not take into account specific mass losses of $\mathrm{HCl}$ from PVC or water from a hydrate sheath.

The relevance of small scale experiments for the determination of fire hazard is a subject of debate. It is generally accepted that Reference Scenario data is an appropriate scale at which to make product comparisons [15]. The following data on commercial cable products was undertaken for FROCC at the fire test facilities SP, Boras, Sweden [16]. Data from three of these tests, of the gaseous combustion products, were analysed and compared with our own results on comparable materials.

Figure 7 compares the $\mathrm{CO}_{2}$ yield as a mass loss ratio for the two power cables and one data cable. There is fair agreement of the $\mathrm{CO}_{2}$ yield for the cross-linked polyolefin, though the completeness of combustion was clearly greater in the full-scale test than in the tube furnace. Mass lost preferentially as water from a hydrate sheath would be undetected in the large scale tests, so the yields of $\mathrm{CO}_{2}$ would be expected to be greater. Further in the tube furnace at $650^{\circ} \mathrm{C}$, very little flaming combustion was observed. (In BS 7990 if flaming is not steady, the temperature of the furnace should be increased in $25^{\circ} \mathrm{C}$ steps until it is). The PVC power cable shows good agreement for the $\mathrm{CO}_{2}$ yields, while the PVC data cable shows less good agreement. The high yield of $2.3 \mathrm{~g} / \mathrm{g}$ suggests that something approaching complete combustion must have occurred in the tube furnace.

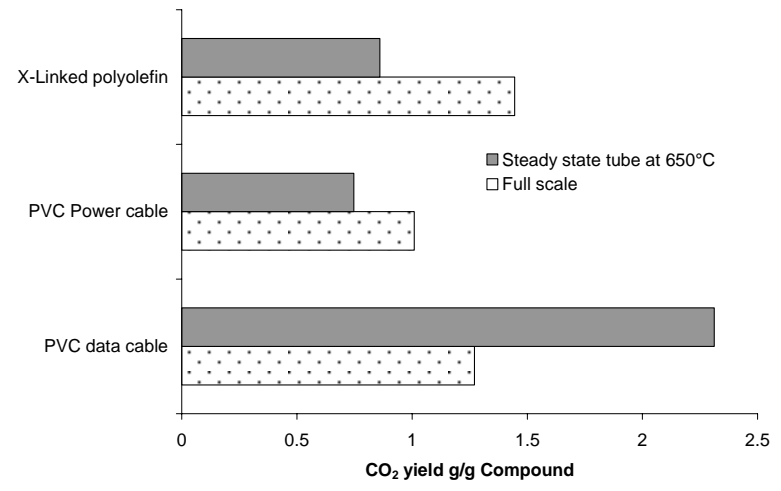

Fig. 7. Comparison of $\mathrm{CO}_{2}$ yield for small and full scale per gram of polymer compound consumed.

Figure 8 compares the $\mathrm{CO}$ yield for the dynamic tube furnace with the full scale measurements. This shows a consistent overestimation of the $\mathrm{CO}$ yield in the tube furnace (which is quite atypical of small scale tests). It may result from quenching of the fire gases by over-ventilation, given the high air flow which would be moving at approximately $200 \mathrm{~mm} \mathrm{~s}^{-1}$, or more efficient quenching by $\mathrm{Cl} \cdot$ radicals of the conversion of $\mathrm{CO}$ to $\mathrm{CO}_{2}$ due to the containment of the plume gases within the tube. The BS 7990 method reduces the initial air flow for the well-ventilated fire condition from 22.6 litre $\mathrm{min}^{-1}$ to 10 litre $\mathrm{min}^{-1}$ (and increases or decreases it depending on the actual oxygen depletion). 


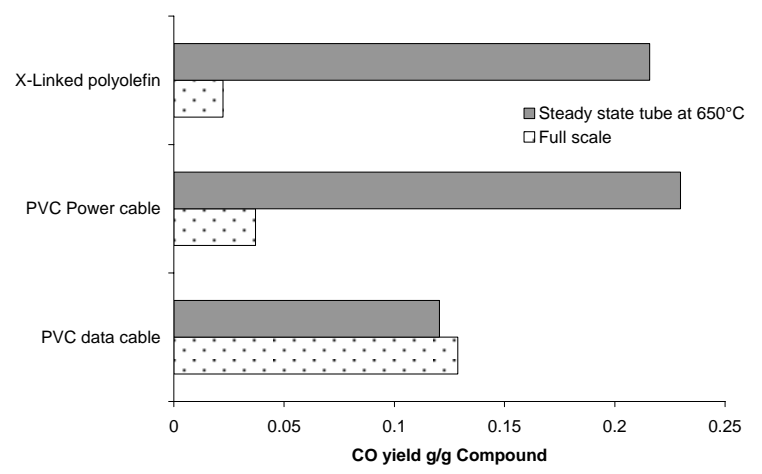

Fig. 8. Comparison of CO yield for small and full scale per gram of polymer compound consumed.

Figure 9 compares the yield of $\mathrm{HCl}$ from the two PVC containing cables in the dynamic tube furnace and real scale test. These show higher $\mathrm{HCl}$ yields from the tube furnace. It is worth noting that compared to the static tube furnace the dynamic tube furnace measurements of $\mathrm{HCl}$ were low. The difference in the fire models (as $\mathrm{HCl}$ is lost quite rapidly from $\mathrm{PVC}$ above $190^{\circ} \mathrm{C}$ ), the availability of surfaces for condensation and trapping of $\mathrm{HCl}$, the degree of formation and oxidation of organochlorine compounds, and trapping by $\mathrm{CaCO}_{3}$ are likely to influence the yield of $\mathrm{HCl}$. These are also likely to have a significant impact on its contribution to the irritancy of fire smoke in a real fire.

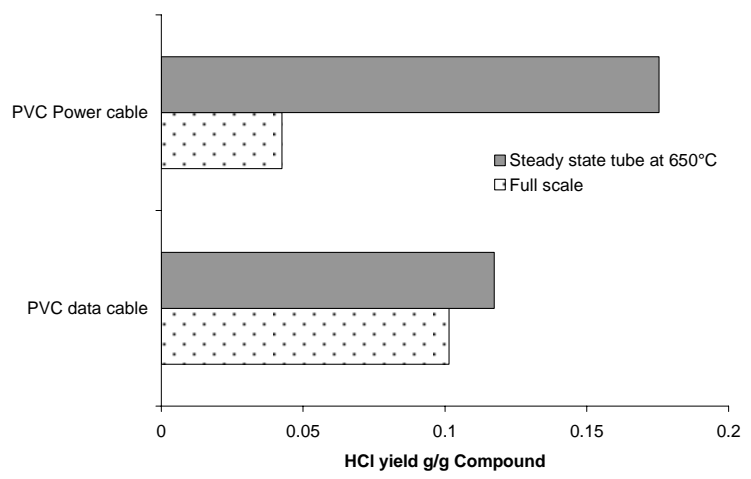

Fig. 9. Comparison of $\mathrm{HCl}$ yield for small and full scale per gram of polymer compound consumed.

\section{CONCLUSIONS}

The results for polypropylene show an excellent correlation between small and large scale, using the equivalence ratio to define the fire condition. The results for the much more complex cable burning show both similarities and differences both within the two types of small scale test, and between the small and large scale tests. The static tube furnace gives more complete combustion of the PVC cable (more $\mathrm{CO}_{2}$ but less $\mathrm{CO}$ ), but less complete combustion of the polyolefin cable, when compared to the steady state apparatus. However, it is difficult to make meaningful comparisons between the two techniques when the results are likely to be most sensitive to the difference in the furnace temperatures of $575^{\circ} \mathrm{C}$ and $650^{\circ} \mathrm{C}$. The small scale tests are generally better defined in 
terms of the individual conditions or fire stages, but the large scale should be closer to representing the real yield over all fire stages. It is difficult to make meaningful comparisons between total yields from real-scale tests, and an individual data point designed to give information on a particular stage of a fire. Further if yields are to be used for comparison purposes, the real-scale data needs to be as full as possible, including accurate mass loss data. Since much of fire toxicity is dependant on orders of magnitude differences, even the apparently poor correlations reported for some determinations are useful.

As every unwanted fire can be assumed to be unique, and there is a requirement to predict the toxic effluent from all likely fire scenarios, data must relate to individual fire stages if it is to be useful for modelling purposes. A strength, and a weakness, of the steady state tube furnace method is that it does not differentiate between materials of high or low flammability. When the methodology has been developed for incorporating yield data into predictions based on fire growth, then much better correlation should be possible.

The methodology in IEC 60695-7-50, which is favoured because of its prescriptive standard testing protocol, has two disadvantages over the more sophisticated BS 7990 (and ISO draft 19700) equivalence ratio approach, which more accurately represents the burning condition and stipulates that either steady flaming or non-flaming occurs for each fire type. In terms of both the small and the large scale data, clear differences between halogenated and halogen free products are reported. The interpretation of these results in terms of hazard is outside the scope of this work and is specific to the installation environment.

\section{ACKNOWLEDGEMENTS}

We would like to thank EPSRC and the European Association of Producers of Flame Retarded Olefinic Cable Compounds (FROCC) for the provision of two project studentships to support this work.

\section{REFERENCES}

[1] "Fire Statistics United Kingdom 2002," Office of the Deputy Prime Minister, London, April, 2004.

[2] Hull, T.R., Quinn, R.E., Areri, I.G., and Purser, D.A., "Combustion Toxicity of Fire Retarded EVA,” Polymer Degradation and Stability, 77, pp. 235-242, (2002).

[3] ISO TS 13571:2001 "Life Threat from Fires - Guidance on the Estimation of Time Available for Escape Using Fire Data.”

[4] BS 7899-2:1999 "Assessment of Hazard to Life and Health from Fire - Part 2: Guidance on Methods for the Quantification of Hazards to Life and Health and Estimation of Time to Incapacitation and Death in Fires," [Fire Types Table p. 18].

[5] Hull, T.R., Carman, J.M., and Purser, D.A., "Prediction of CO Evolution from Small-scale Polymer Fires,” Polymer International, 49, pp. 1259-1265, (2000).

[6] Purser, D.A., Fardell, P.J., Rowley, J., Vollam, S., Bridgeman, B., and Ness, E.M., "An Improved Tube Furnace Method for the Generation and 
Measurement of Toxic Combustion Products Under a Wide Range of Fire Conditions," Proceedings of the Flame Retardants '94 Conference, Interscience Communications, London, 1994.

[7] Hirschler, M.M., "Smoke Toxicity: Yields of Toxicants in Fires and Implications for Lethality and Incapacitation,” Recent Advances in Flame Retardancy of Polymeric Materials, 10, (1999), BCC, Connecticut, USA.

[8] Beyler, C.L., "Major Species Production by Diffusion Flames in a Two-layer Compartment Fire Environment," Fire Safety Journal, 10, pp. 47-56, (1986).

[9] Pitts, W.M., "The Global Equivalence Ratio Concept and the Formation Mechanisms of Earbon-monoxide in Enclosure Fires," Progress in Energy and Combustion Science, 21, pp. 197-237, (1995).

[10] Blomqvist, P., and Lonnermark, A., "Characterization of the Combustion Products in Large-scale Fire Tests: Comparison of Three Experimental Configurations," Fire Mater., 25, pp. 71-81, (2001).

[11] Babrauskas, V., Parker, W.J., Mulholland, G., and Twilley. W.H., "The Phi Meter: A Simple Fuel-independent Instrument for Monitoring Combustion Equivalence Ratio,” Rev. Sci. Instrum., 65, pp. 2367-2375, (1994).

[12] Hermansson, A., Hjertberg, T., and Sultan, B.A., "The Flame Retardant Mechanism of Polyolefins Modified with Chalk and Silicone Elastomer," Fire and Materials, 27, pp. 51-70, (2003).

[13] Sultan, B.Å., and Paul, K.T., "Combustion Atmosphere Toxicity of Polymeric Materials Intended for Internal Cables," Accepted for publication in Fire and Materials.

[14] Robinson, J.E., Samson, F., and Sultan, B.Å., "Determination of the "Real Time" Yield of Toxic Fire Gases as Input for the Simulation of People Evacuation," Accepted for publication in Fire and Materials.

[15] Robinson, J.E., Sultan, B.A.., and Samson, F., "The Development of Toxic Gas Yield in a Format Suitable for Evacuation Modeling," Proceedings of the 10th International Fire Science and Engineering Conference (Interflam), 2004, p 781-786.

[16] Grayson, S.J., Van Hees, P., et al, "The FIPEC Report, Fire Performance of Electric Cables,” Interscience Communications Ltd, London, 2000.

[17] Robinson, J.E., "Reference Scenario Fire Testing of Cables,” Cables Conference 2003, Köln, 2003. 